\title{
RECURSOS PEDAGÓGICOS COMO APOIO DOCENTE: UM RELATO DE EXPERIÊNCIA NO CURSO DE ADMINISTRAÇÃO
}

\section{PEDAGOGICAL RESOURCES AS A TEACHER SUPPORT: A REPORT OF EXPERIENCE IN THE COURSE OF ADMINISTRATION}

\author{
Jhony Pereira Moraes ${ }^{1}$ \\ https://orcid.org/0000-0002-1669-9181 \\ Raquel Prá \\ https://orcid.org/0000-0001-6189-5395 \\ Geneia Lucas dos Santos ${ }^{3}$ \\ https://orcid.org/0000-0002-9544-1196
}

Recedo em: 31 jan. 2018.

Aceito em: 15 dez. 2020.

\section{RESUMO}

A mudança no perfil dos estudantes ingressantes e dos egressos do ensino superior exige dos docentes a adoção de um novo perfil e a utilização de novas práticas. Com base neste contexto, este trabalho de caráter descritivo tem por objetivo fazer um relato de experiência sobre a prática docente, por meio da apresentação de quatro recursos pedagógicos utilizados na disciplina de Ensino-Aprendizagem em Administração, no Programa de Pós-graduação em Administração da Universidade Federal do Rio Grande Sul (UFRGS). São estas as ferramentas: Kahoot!, EAD Builder, Mindmeister e CANVA. Pretende-se por meio deste contribuir para novas pesquisas sobre metodologias de ensino e recursos pedagógicos.

Palavras-chave: Recursos pedagógicos; Kahoot!; EAD Builder; Mindmeister; CANVA.

\begin{abstract}
Changes in the profile of incoming students and higher education graduates requires that teachers adopt a new profile and use new practices. Based on this context, this descriptive work aims to make an experience report about the teaching practice, through the presentation of four pedagogical resources used in the discipline of Teaching-Learning in Administration, in the Graduate Program in Administration of Federal University of Rio Grande Sul (UFRGS). They are the tools: Kahoot!, EAD

1 Jhony Pereira Moraes. Mestrando em Administração (UFRGS/PPGA/Gestão de Pessoas). E-mail: jhonymoraes@hotmail.com.br.

2 Raquel Prá. Mestranda em Administração (UFRGS/PPGA/Gestão de Pessoas). E-mail: raquel.pra@hotmail.com.

${ }^{3}$ Geneia Lucas dos Santos. Doutoranda em Administração (UFRGS/PPGA/Gestão de Pessoas). Email: geneialucas@gmail.com.
\end{abstract}


Builder, Mindmeister and CANVA. It intends to contribute to new research on teaching methodologies and pedagogical resources.

Keywords: Pedagogical resources; Kahoot!; EAD Builder; Mindmeister; CANVA.

\section{INTRODUÇÃO}

Lourenço, Lima e Narciso (2016) evidenciam que a mudança no ensino superior brasileiro nas últimas décadas vem despertando a atenção de professores e instituições para a formação pedagógica docente. Observa-se uma transformação no perfil dos estudantes ingressantes e dos egressos, assim como exige-se um novo perfil docente; sendo sua prática complexa, cada vez mais direcionada (caráter especialista) e situada na realidade.

Filho e Ribeiro (2007) salientam que o alto volume de conhecimentos apresentados e apreendidos corrobora para a rápida obsolescência do aprendizado, sendo, portanto, fundamental promover novas formas de conhecimento e habilidades de trabalho, sobrepondo conteúdos enraizados na prática docente e desatualizados. Filho e Ribeiro (2007, p. 2) defendem ainda que "para transformar o status quo da sala de aula universitária é urgente reconhecer os objetivos educacionais e adotar abordagens alternativas ao ensino tradicional".

Berbel (2012) reflete sobre a autopercepção do profissional enquanto docente. Para a autora é essencial que se faça uma reflexão sistemática sobre as práticas, de maneira que possam atender às necessidades sociais.

Nesse sentido, este trabalho tem por objetivo fazer um relato de experiência sobre a prática docente, por meio da apresentação de recursos pedagógicos utilizados na disciplina de Ensino-Aprendizagem em Administração, no Programa de Pósgraduação em Administração da Universidade Federal do Rio Grande Sul (UFRGS). $\mathrm{O}$ trabalho tem caráter descritivo e busca contribuir para novas pesquisas sobre metodologias de ensino e recursos pedagógicos.

\section{MATERIAL E MÉTODOS}

Este relato de experiência é resultante das inquietações e questionamentos de dois alunos do Programa de Pós-graduação em Administração da UFRGS. As práticas 
docentes apresentadas neste trabalho são oriundas das atividades docentes desenvolvidas na disciplina de Ensino-Aprendizagem em Administração, que tem como objetivo maior o exercício da atuação e reflexão de mestrandos e doutorandos em relação à profissão docente na área administrativa. A construção da disciplina citada ocorreu através da elaboração de seminários, sob responsabilidade dos discentes. Os assuntos foram distribuídos nos primeiros encontros. Todos tinham como missão abordar os conteúdos apresentando-os aos demais alunos de diferentes formas.

Assim, apresentam-se aqui quatro ferramentas pedagógicas empregadas em alguns seminários pelos pesquisadores, sendo elas: Kahoot!, EADBuilder, Mindmeister e CANVA.

\section{RESULTADOS E DISCUSSÃO}

O Kahoot! trata-se de um jogo digital utilizado como recurso didático, que permite a criação de quizzes, pesquisas e discussões para promoção de competições entre alunos. Por meio da ferramenta, docentes podem lançar perguntas com o intuito de introduzir novos conhecimentos ou revisá-los. Também é possível estabelecer pontuações para cada pergunta. Ao final do jogo, gera-se um ranking com os melhores colocados. Como recursos adicionais permite-se a inclusão de vídeos, imagens e música ao jogo. O objetivo do sistema é tornar a aprendizagem um processo divertido (DELLOS, 2015; KAHOOT!, 2017;)

O EADBuilder consiste em uma ferramenta gratuita (versão para teste) e/ou paga disponibilizada online para a criação de cursos interativos voltados para o ensino à distância. O site disponibiliza cenários, personagens e objetos que podem ser manuseados para criar ambientes de aprendizagem compostos por históricos de forma simplificada e rápida. Como principal vantagem, ressalta-se que sua interface permite trabalhar com designs atrativos sem precisar de conhecimentos da área de desenvolvimento e programação (EADBUILDER, 2017).

Mindmeister é uma ferramenta disponibilizada online pela Google para criar mapas mentais. Caracteriza-se por ser colaborativa, permitindo que os mapas sejam construídos em conjunto e que as pessoas interajam por intermédio de um bate-papo 
disponibilizado no site. A modalidade básica permite criar no máximo três mapas e é gratuita, mas existem outras opções pagas (CASTAMAN; INOCENTE, 2016; MINDMEISTER, 2016).

O CANVA consiste em uma ferramenta para criação de design gráfico que permite a alunos e professores a criação de materiais para cartazes, apresentações e posts para serem incluídos nas mídias sociais. São disponibilizados diferentes tipos de imagens e letras, a maior parte gratuitos, porém alguns designs são pagos (CANVA, 2017).

O Quadro 1 a seguir, faz uma síntese das ferramentas e suas finalidades.

Quadro 1: Ferramentas analisadas

\begin{tabular}{|l|l|l|}
\hline Ferramentas & Tipo/Objetivo & Finalidade \\
\hline Kahoot! & Jogo & Realização de competições, introdução e revisão de conteúdos. \\
\hline EAD Builder & Plataforma EAD & Criação de cursos interativos para ensino à distância. \\
\hline Mindmeister & Mapas mentais & Criação de mapas mentais construídos interativamente. \\
\hline CANVA & Design Gráfico & $\begin{array}{l}\text { Criação de materiais de apresentações, cartazes e posts para as } \\
\text { redes sociais. }\end{array}$ \\
\hline
\end{tabular}

Fonte: elaborado pelos autores (2017).

\section{CONSIDERAÇÕES FINAIS}

A disponibilidade das ferramentas analisadas - Kahoot!, EADBuilder, Mindmeister e CANVA - permitem aos docentes inserir novas metodologias em suas práticas pedagógicas e também interagir de formas inovadoras com os alunos. Estas são formas distintas e inovadoras para buscar promover maior engajamento na relação de ensino e aprendizagem.

Introduzir mudanças no processo de ensino não é tarefa simples, pois a inclusão de novas metodologias deve ser analisada de forma crítica. Cabe salientar em relação a este aspecto que estas devem ser adaptadas ao objetivo de ensino, tipo de conteúdo a ser trabalhado e também ao perfil dos alunos.

O estudo do funcionamento de ferramentas é o primeiro passo para a escolha de novas metodologias de ensino. Sugere-se que estudos futuros busquem relatar os resultados obtidos por professores e alunos com a utilização destes instrumentos para fornecer maiores subsídios aos docentes para a realização do planejamento de suas atividades. 


\section{REFERÊNCIAS}

BERBEL, N. A. N. As metodologias ativas e a promoção da autonomia de estudantes.

Seminário: Ciências Sociais e Humanas, v. 32, n. 1, p. 25-40, 2012.

CANVA. Disponível em: https://about.canva.com/pt_br/. Acesso em: 24/8/2017.

DELLOS, R. Kahoot! A digital game resource for learning. International Journal of Instructional Technology and distance learning, v.12, n. 4, 2015.

EAD BUILDER. Disponível em: http://www.eadbuilder.com.br/. Acesso em: 24/8/2017.

FILHO, E. E.; RIBEIRO, L. R. C. de. Inovando no ensino de administração: uma experiência com a Aprendizagem Baseada em Problemas (PBL). Cadernos EBAPE. BR, 2008.

INOCENTE, L; CASTAMAN, A. S. Mapas conceituais digitais: relevância no processo de ensino e aprendizagem.

KAHOOT!. Disponível em: https://kahoot.it/. Acesso em: 24/8/2017.

LOURENÇO, C. D. da S.; LIMA, M. C.; NARCISO, E. R. P. Formação pedagógica no ensino superior: o que diz a legislação e a literatura em Educação e Administração?. 2013.

MINDMEISTER. Disponível em: https://www.mindmeister.com/. Acesso em: 24/8/2017. 